\title{
APRENDIZAGEM DA DOCÊNCIA EM UMA ESCOLA DO CAMPO: RESSIGNIFICAÇÕES NA TRAJETÓRIA DE PROFESSORES
}

\author{
LEARNING TO TEACH IN THE RURAL SCHOOL: \\ NEW MEANINGS IN THE TRAJECTORY OF TEACHERS
}

\author{
Juliana Pereira de Araújo* \\ Rosa Maria Moraes Anunciato de Oliveira**
}

\begin{abstract}
Resumo: Tendo como fonte um trabalho de doutorado, procuramos compreender os aspectos sobre a aprendizagem da docência em uma escola do campo através do olhar dos sujeitos envolvidos. A revisão bibliográfica enfoca alguns conceitos como a oposição "urbano/rural” e "saberes docentes”. A partir da análise de narrativas de quatro professores que atuam em uma escola do campo situada em AraraquaraSP, procuramos evidenciar que para os professores vindos do ambiente urbano e que atuam no campo a docência se constrói inicialmente influenciada por sua experiência urbana e pela frágil elaboração de ideias sobre a história de marginalidade e de luta pela reforma agrária que marca o ruralismo pedagógico para os sujeitos da escola do campo. Nesse sentido, os docentes acionam conhecimentos superficiais para adaptação ao contexto, sem considerar várias experiências e elementos específicos dessas escolas que, quando vivenciados, potencializam processos de ressignificação profissional, mobilizando novas conformações dos conhecimentos docentes e impulsionando a constituição de outros saberes ainda pouco desenvolvidos. A docência nesse espaço precisa ser mapeada e melhor compreendida para enriquecimento da educação e concretização de um projeto nacional que possa integrar campo e cidade.
\end{abstract}

Palavras-chave: Formação de professores. Educação do campo. Aprendizagem da docência.

Abstract: Deriving from a doctorate's work, we seek to understand the aspects of learning how to Based on a doctoral study, this article tries to understand aspects related to learning to teach in a rural school from the perspective of the subjects involved. The literature review focus on some concepts such as the opposition between "urban/rural" and "knowledge teaching". From the analysis of the narratives provided by four rural school teachers who work in Araraquara-SP, the study aimed to demonstrate that for those teachers that work in rural schools but come from an urban environment, teaching is initially built under the influence of their urban experience and the fragile formulation of ideas about the history of marginality and struggle for the agrarian reform that mark rural pedagogy. Accordingly, these teachers activate superficial knowledge in order to adapt to the context without taking into consideration specific elements and experiences from those schools that when experienced, leverage professional reframing, mobilizing new teaching-knowledge conformations and prompting the constitution of different, underdeveloped knowledge. Teaching in this context needs to be mapped and

\footnotetext{
* Professora do Departamento de Educação Geral da Universidade do Estado do Pará. Doutora em Educação pela UFSCar.<juliana.barrado@gmail.com>

* Professor at the Department of General Education from the University of the State of Pará. Doctor in Education from the Federal University of São Carlos. E-mail: < juliana.barrado@gmail.com>.

** Professora da Universidade Federal de São Carlos. Doutora em Educação pela UFSCar. E-mail: <rosa@ufscar.br>.

${ }^{* *}$ Professor at the Federal University of São Carlos. Doctor in Education from the Federal University of São Carlos.

E-mail: <rosa@ufscar.br>.
} 
better understood for the enrichment of education and the establishment of a national project that can integrate the city and the countryside.

Keywords: Teacher education. Rural education. Learning to teach.

\section{Introdução}

Desde a segunda metade do século vinte verificamos a expansão das demandas sociais por uma educação mais democrática, acessível e concatenada com a realidade cada vez mais heterogênea em identidades e culturas. Surgem e ressurgem escolas diferenciadas originadas na multiplicidade de lugares, culturas e comunidades que constituem um grande mosaico educacional de cores, valores e costumes muito diferentes, questionam a visão unicista de uma educação brasileira para todos e coalizam ações que apontam a necessidade de planos de educação setoriais, por modalidades. Daí a educação ribeirinha, a educação quilombola, a educação inclusiva e algumas outras, como a educação do campo, que é talvez a mais antiga iniciativa de "setorialização", aqui entendida como iniciativa de "adequação" às demandas populares da educação no Brasil.

Tornar-se professor nesse contexto polivalente é passar, inexoravelmente, por uma crise de identidade profissional, na medida em que a estrutura burocrática de gestão da estrutura organizacional da educação no microcosmo das escolas e redes municipais não é contingenciada por elementos básicos como, por exemplo, a dedicação exclusiva dos professores em tempo integral nas escolas. Assim, os professores comumente são pressionados no dia a dia a desenvolver sua profissionalidade a partir das experiências vividas em ambientes absolutamente díspares entre si - como a escola pública de periferia, a escola particular da classe média e a escola do campo -, no que tange à teorização das ações e da reflexão. Existem professores que fazem essa verdadeira procissão, já que o campo muitas vezes é um prolongamento geográfico da cidade, o chamado "rurbano".

Por isso, é compreensível que a escola tenha se tornado lócus de incerteza no qual a busca pela mudança é uma contingência emergencial. (CANÁRIO, 2006). Para Imbernón (2005, p. 100), “as profundas transformações ocorridas no último século na dimensão educativa tornam a situação de ensino incerta, única, complexa e portadora de um conflito de valores na definição das metas e na seleção dos meios".

Entre esses dilemas e imposições persiste um professor que fundamenta sua prática em discursos atrelados ao paradigma positivista e metodologias que mantêm sua atividade no eixo de uma relação verticalizada entre Estado, currículo, professores e alunos, em que priva os últimos de quaisquer traços de autonomia (CONTRERAS, 2002). E quanto mais apegado a esse eixo, mais distante da profissionalização docente fica esse professor.

Mas, perpassando esse painel e consolidando novo arsenal de reflexões e concepções que se sustentam com vias à profissionalização da docência por outra ideia de formação, por outro paradigma - no qual tanto o campo como outros espaços são contemplados -, a mudança tem acontecido. 


\section{O campo: um velho conhecido, mas um novo a conhecer}

A imersão no cotidiano do campo por meio de uma pesquisa desenvolvida desde 2002 nos mostrou que a realidade não é tão homogênea e linear quanto o termo sugere. Não creditamos a existência de "campo" como conceito universalizante, mas como um conceito agrupador, um "guarda-chuva" que abriga realidades com matizes do rural, da floresta, do rio, da aldeia, da comunidade quilombola, do assentamento cujo ponto comum é a relação direta com a natureza, com o "rural" em sua vida cotidiana, seu sustento, sua socialização. Possui sujeitos que não seguem teorias urbanocêntricas, mas alimentam outras visões, outras possibilidades, como se tem feito, por exemplo, na questão do desenvolvimento sustentável.

O estudo do conceito de "campo" ou da terminologia "rural", anteriormente utilizada, traz de início constatações importantes. Temos visões que lhe outorgavam a extinção, como a de Lênin (1988), na qual se previa que esse estudo simplesmente desapareceria com o desenvolvimento do capitalismo. Em outras visões, como a de Kautsky (1986), o campo teria sido completamente acoplado ao sistema agroindustrial capitalista (hoje denominado CAI - Complexos Agroindustriais), como fornecedor primário aos grandes produtores monocultores.

De qualquer forma, o campo persiste nessa sociedade dita "do conhecimento" (CASTELLS, 1979). Resfolega em pequenos espaços verdes, e sim, há escolas neles, e professores, nascidos ali ou forasteiros vindos da cidade. O campo não só sobreviveu como se modificou, tanto no sentido de avançar no modelo capitalista como previa Kautsky (1986) (cite-se o exemplo das pequenas empresas agrícolas familiares ligadas aos CAI), como no sentido de pontuar divergências, afastamentos a um modelo social injusto baseado na exploração das desigualdades e propriedades marcadas pela produção de subsistência. Nessa trajetória de modificação, destacamos o reaparecimento da luta pela reforma agrária, agora liderada e fortalecida por movimentos sociais pela terra.

São os movimentos pela reforma agrária que diversificam, no estado de São Paulo, o mapa dos espaços rurais, fortalecem o acesso à utilização da terra e das forças produtivas da agricultura familiar, que é reconhecida pelo baixo impacto ambiental. Tanto a pequena agricultura familiar tradicional (de proprietários de terra) quanto a agricultura familiar, que brota nos assentamentos, são ricas nas manifestações que caracterizam seus espaços, seus sujeitos e relações. Ainda que possam passar por processos de desruralização (WHITAKER e ANTUNIASSI, 1992), mantêm o cerne que é a identificação com a terra, com a ideia de que é direito do homem viver na terra e da terra.

Para Whitaker (2002), por serem definidos em uma "paradoxal realidade", na qual mesclam nuances variadas de interlocução entre si, esses espaços podem ser descritos e entendidos como "franjas do rural-urbano". Segundo a autora, isso pode ser observado quando:

No espaço que se queria rural a monocultura de cana estabelece ruas, placas, quarteirões. No espaço que se expressava como urbano, quintais plantados com hortas e criações, pequenas chácaras, flores e pássaros por toda parte. (WHITAKER, 2002, p.35)

Com estas considerações sobre o campo é possível avançarmos na ideia basal de que há, de fato, especificidades no campo que o fazem destoar dos modelos urbanos densamente impostos e difundidos. E por isso ele 
apresenta outros modelos ou paradigmas de vida e produção, dos quais a educação ainda não se aproximou adequadamente nem em discurso, nem em práticas.

Não sabemos até que ponto a sociedade que tem sido denominada "do conhecimento" ignora ou coopta a realidade do campo, mas podemos julgar que ela não é vista em sua totalidade, mas sim através de um ângulo reducionista que busca manter o campo no eixo do aceito e do propalado, o eixo do "mesmo".

Os saberes, os conhecimentos, as competências e caminhos profissionais dos professores do campo são influenciados, portanto, por orientações diversas. Enquanto classe profissional, professores formam um grupo marcado pela heterogeneidade identitária em atenção às múltiplas realidades e assumem uma miríade de técnicas, concepções e jeitos de ser, fazer e ensinar. Mas à jusante desta dinâmica, campo e cidade polarizam essas atuações. E em uma primeira leitura se afastam.

\section{Professores do campo: pela superação do "mesmo" e por outro paradigma}

Entendemos que a docência, hoje, precisa transcender o "mesmo", o comum, o igual, o fixo. Absorvemos, ao longo dos séculos, o mesmo modelo de professor, de aluno e de educação. Achávamos que a mesma avaliação bastaria, os mesmos materiais seriam adequados, mas não. Os tempos recentes nos trouxeram, pela força dos movimentos sociais (GOHN, 1997), a valorização do outro, da diversidade, do distante, do escondido. A docência tenta se adequar, se encaixar nas novidades sociais. Professores inclusivos, quilombolas, indígenas. Professores com capacidades para, como indica Imbernón (2005),
Superar definitivamente os enfoques tecnológicos, funcionalistas e a burocratização antes da instituição educativa, aproximando-se, ao contrário, seu caráter mais racional, mais dialógico, mais cultural-contextual e comunitário, em cujo âmbito de importância a relação se estabelece entre todas as pessoas, que trabalham dentro e fora da instituição. (IMBERNÓN, 2005, p. 8).

Suplantar a formação técnica racional é preciso, porque a evolução da história da sociedade tornou a educação dos seres humanos pouco a pouco mais complexa e a profissão docente reflete esse processo, tornando-se também mais complexa. A apreensão desse novo horizonte pelos professores precisa, então, de um movimento de imersão local e emersão global e vice-versa. Olhar para si mesmo e para o todo num acerto de contas dialógico e constante. Esse é um processo em que vão sendo delimitadas as fronteiras identitárias da profissão e que estabelece o teor da complexidade das escolas no mundo contemporâneo.

Vemos, a partir das leituras até aqui expostas, que se por um lado estão dadas as características da sociedade, por outro estão indefinidas as da escola nos dias atuais. Simultaneamente, destacamos a existência de realidades que não são diretamente condicionadas pelo modelo hegemônico de educação urbana, que são as comunidades do campo, ribeirinhas, onde emergem escolas com valores e projetos diferentes, tangenciadas pelo local.

Chegamos então a um ponto de nossa reflexão no qual podemos sustentar basicamente que a função da escola sobrevém da construção local e socioculturalmente determinada pela própria escola em sua dialogicidade com os sujeitos que a constituem. Construção que atinge, enquanto identidade, escolas de mesma conjunção tornando-as unificadas, compartilhantes de missões de 
mesmo norte e que nem por isso as aliena, pois que ainda lhes dá condições de atuação no mundo.

As escolas do campo categorizariam uma dessas esferas escolares, modalidades ou classes. Possuem identidade, estão em vias de construí-la, possuem demandas próprias, aspectos próprios, mas professores que na maioria não lhe pertencem e não sentem pertencimento por ela, porque não transitam em seu universo. Parece, porém, que terão de se comprometer com ela, inserir-se em sua realidade, como necessidade básica para uma carreira de vida longa (KNOWLES \& COLE, 1994). É esse continuum que nos impõe a admissão de nosso inacabamento humano e, portanto, a capacidade de assumir riscos, de nos reinventar (FREIRE, 1997).

Neste painel algumas indagações nos acompanham e instigam as reflexões do presente texto: no que a mudança para a escola do campo afeta os professores? Como eles fundamentam sua prática e como concebem sua função em um lugar que se estabelece muitas vezes fora do eixo de reprodução do capital através da subsistência e da agricultura familiar?

Admitimos o processo reflexivo, ainda que entendido de modo diverso por diferentes autores, como aspecto importante para aprender a ser professor (SCHON, 1983, 2000; FREIRE, 1997; PIMENTA \& GHEDIN, 2002). Compreendemos a reflexão como ferramenta para que se consolidem professores com capacidade para responder tanto à complexidade do ambiente tecnológico da sociedade da informação, quanto aos questionamentos que estão na base de todo processo educativo: ensinar o quê? Para quem? Por quê? Como?

É a reflexão que cava explicações sobre a mudança social das escolas e que perscruta nessa mudança a real importância e rumo da valorização dos professores. É a reflexão que não permite sucumbirmos da responsabilidade de nos adaptarmos criticamente aos novos padrões e ditames.

Inevitavelmente, o procedimento reflexivo configura-se como um processo de conquista da autonomia frente a condições que tentam controlar o trabalhador, no caso o professor, e que impõem sutilmente a perda da autonomia dos professores influindo em suas práticas de ensino, arrefecendo o seu poder no desenvolvimento de situações que instiguem nele e nos estudantes o senso crítico e propiciem o êxito do processo de ensino-aprendizagem. Movimento de libertação que Freire (1997) corretamente apresentou como sendo doloroso e complexo.

Sente-se, cada vez mais, a necessidade de resgate da autonomia que luta contra a simplificação da docência, que nos faz desacreditar que o ensinar seja apenas dar certezas de forma afetuosa, trilhar caminhos seguros quando justamente podemos cooperar para a recusa ao status quo, para a contestação e experimentação. A autonomia não nos tira a necessidade de mergulhar na diversidade cultural, que nos é fator de maior estranhamento, mas nos prepara para mergulhos mais profundos, mais longos, em águas turvas.

Nossas caminhadas pelo campo, nossas buscas e prospecções sobre a docência do campo foram amparadas pela utilização das narrativas enquanto metodologia.

\section{De onde vem nosso olhar: as narrativas enquanto metodologia}

As narrativas, histórias e biografias são cada vez mais usadas por investigadores das ciências humanas, sobretudo por aqueles que têm a sociologia e a educação como 
campo de estudo e ação. Sua utilização se dá por serem tidas como trocas de experiências que fundamentam a educação humana, sendo, portanto, originadas de uma “construção sócio-histórica e cotidiana das narrativas pessoais e sociais” (SOUZA \& ABRAHÃO, 2006). A escola é palco de muitas histórias e as narrativas desses fatos ampliam o entendimento das ricas interações entre sujeitos professores, alunos e muitos outros elementos ali presentes.

Especialmente na área da educação, Elbaz (1990) é uma das autoras que defendem o recurso à investigação narrativa, argumenta que as "histórias são o material de ensino, a paisagem em que vivemos como professores e investigadores e através da qual o trabalho dos professores pode ser visto como fazendo sentido” (p. 32).

As narrativas utilizadas para a elaboração deste artigo foram colhidas entre os anos de 2007 e 2009 e ampararam as análises pertinentes a um trabalho de doutorado, cujo objetivo era acessar, através das narrativas de professores de um assentamento rural localizado em Araraquara, interior de São Paulo, pistas sobre a constituição da docência no campo.

A escolha dos professores colaboradores da pesquisa foi dirigida pela intenção de analisar os docentes do ciclo I do ensino fundamental (primeiro ao quinto ano) e também dos chamados PII, que são professores do segundo ciclo (sexto ao nono ano). Na ocasião, a escola possuía quatro professoras do ciclo I e sete professores do ciclo II, sendo que quatro professores aceitaram participar da pesquisa. Aqui eles serão tratados por $\mathbf{O}$, $\mathbf{M}, \mathbf{R}$ e $\mathbf{J}$; os dois primeiros são do ciclo I (PI) e os dois segundos do ciclo II (PII).

$\mathbf{M}$ era professora na escola desde 2000, assim como O; tinha 46 anos na época da pesquisa, trabalhava com a terceira série e cursou pedagogia em uma universidade pública de Araraquara. O contava com 62 anos e trabalhou durante muito tempo em grandes empresas do setor citrícola; após a aposentadoria passou a se dedicar à educação lecionando na escola, mas antes disso teve experiências como substituta, monitora e funções afins em cursos comunitários. J tinha 27 anos, era bióloga, possuía mestrado pela Universidade Federal de São Carlos; apesar de a docência não ter sido uma opção por ela considerada, lecionava na escola desde 2007, após aprovação em concurso público. $\mathbf{R}$ tinha 26 anos e era formado em Educação Física; também iniciou suas atividades como professor na escola a partir da aprovação em concurso, lá chegando em 2007. Possuía experiência em escolas estaduais e, assim como $\mathbf{J}$, mantinha-se em atividade na escola do assentamento e também em escolas estaduais de Araraquara.

Esses quatro professores concederam entrevistas no primeiro semestre de 2008, de aproximadamente uma hora cada um. No decorrer do mesmo ano foram realizadas duas ou três entrevistas com cada um dos professores e nelas, através da narrativa oral, foram apresentados os eixos centrais para reflexão como os motivos que influenciaram na escolha pelo magistério, a entrada na carreira, a chegada ao campo e as práticas pedagógicas.

Após as entrevistas foi realizada a transcrição e textualização das histórias a partir das contribuições de Fiamengue (2004). Seguindo o manual de história oral de Meihi (2005), as transcrições foram devolvidas aos professores para que realizassem a correção ou mesmo a omissão dos trechos que considerassem de alguma forma invasivos e/ou comprometedores. Também poderiam complementá-las do modo como quisessem. Essa tarefa fez com que os entrevistados passassem do papel de autores contadores ao de autores escritores. Com isso, 
obtivemos narrativas que não teriam sido atingidas apenas com as entrevistas, com as narrativas orais. Os excertos apresentados a seguir foram pinçados das entrevistas textualizadas e organizados em blocos temáticos.

A partir de agora centraremos nossa atenção nos excertos das narrativas que consideramos pontos de ressignificação docente: a chegada ao campo e as alterações percebidas na prática educativa.

\section{O ponto zero: a chegada ao campo}

Os trechos que explicitam a chegada ao assentamento dão a dimensão da distância entre três modelos de escola: a escola “idealizada", presente nos textos legais, nas diretrizes, nas tendências pedagógicas das licenciaturas; a escola pública do meio urbano, que é o modelo hegemônico e impregnado de significados ruins; e a escola concreta, real, incrustada no campo, formada de pequenas impressões, idealizações, mas que era totalmente desconhecida por aqueles professores que lá iriam exercer a docência. A surpresa no momento da chegada mostra esse desconhecimento, o preenchimento de sua concepção com base em pré-julgamentos sobre o rural, o campo, um lugar onde não há nada.

"Acordei 5 horas da manhã, já fui pensando "Onde vim parar? Educação? Nem imaginava muito menos escola de campo (...). Imaginei se era de madeira, se era barraca no meio do nada. Pra mim era barraca no meio do nada". Cheguei aqui e falei: - Nossa!" (J.)

"Aí, você fica pensando... Como é que era o que tem uma perspectiva de como é um ambiente. E aí, como é isso... na entrada de terra e tudo era terra. Pensava que não tinha quadra, não tinha nada disso." (M.)
Simbolicamente o que os professores esperam encontrar, possivelmente por se restringir ao acesso pessoal as exposições que a mídia proporciona, é a imagem do barracão de lona preta. O ruralismo pedagógico parece estar na base conceitual sobre o campo e seus habitantes. Esperam o aluno pobre, o “jeca tatu”, e a ele dimensionam inicialmente uma educação plagiada, higienista até. Quase uma colonização educacional.

É a partir da chegada, do impacto, que se inicia a assimilação da heterogeneidade de identidades escolares marcadas:

Por suas condições cotidianas de vida, pela classe à qual pertence, pelo grupo imediato através do qual pertence a ela, e pelo lugar que ocupa na divisão do trabalho, por seu lugar na família e por sua história escolar em parte. Em parte, porque o sujeito também contribui para a constituição de todas essas situações (EDWARDS, 1997, p. 15).

Tal contraste sociocultural mostra aos professores da cidade que as ações dos alunos do campo precisam ser compreendidas nesse espaço de múltiplas determinações.

Tomamos da perspectiva de Forquin (1993) a base teórica para, assim como ele, considerar que "a escola é um mundo social, que tem suas características próprias, seus ritmos, ritos, linguagem, imaginário, modos próprios de regulação e de transgressão, seu regime próprio de produção e de gestão de símbolos” (FORQUIN, 1993, p.167). Nesse sentido, a cultura da escola diz respeito às características de produção de cultura pela escola, através das relações que se estabelecem no cotidiano educativo.

Pensando assim, concordamos que essa instituição, a escola, não se configura apenas como espaço de reprodução social, mas também de produção. Produção e reprodução marcadas pela sua localização em um 
diferencial tão complexo que se formaliza na própria terminologia: campo, do campo, no campo, para o campo... Essa distância, que é a princípio meramente geográfica em relação à urbe, é citada várias vezes, porém com o tempo vai se ressaltando não apenas a geografia, mas a distância entre as realidades, as culturas, as identidades. Quando falam da distância, os professores logo relacionam a ela o desgaste físico.

"Você vê que tudo é muito longe da escola... Agora no momento estou morando em Araraquara, porque eu era de Matão. Então eu saía quatro e meia de Matão, vinha para Araraquara, deixava a moto no local. Num posto de gasolina. Pegava às seis e meia, aí eu vinha até aqui no assentamento." (R.).

"Menina, no primeiro mês eu voltava morrendo de dor no corpo. Quando chovia parava na estrada. Parava na entrada e a gente subia amassando barro com água na canela. Não tinha professor pro sétimo, oitavo ano. Não, de quinto ano não tinha... Professores primários estavam trabalhando com essas crianças." (M.).

Podemos assinalar que é a partir da chegada à escola, sendo esse um dos primeiros momentos de reconhecimento da realidade, de seus tempos e espaços, que surge a necessidade de modificação na docência. Logo nos primeiros dias os professores notam que nesse espaço a prática educativa não é pautada pela valorização do verbalismo, que é visível nas escolas urbanas, majoritariamente propedêuticas. A prática ali não se volta para a pavimentação das possibilidades do futuro, mas para a transformação das condições presentes.

"Não têm cartilhas, não têm nada direcionado ao campo, você tem que se virar e buscar. Ir adaptando material. Você não acha que dentro da reforma agrária não era pra ter isso já? É tudo urbanizado, da cidade, e a gente tenta buscar." (O.).

Essa é uma exigência que se torna dificultosa sem a formação continuada. Vejamos esta questão.

\section{Formação continuada: continua ou recomeça?}

Em algumas entrevistas as narrativas adentraram na questão da formação continuada para os professores do campo. A fala dos professores pontua a inexistência de iniciativas governamentais concretas no sentido de valorizar ou investir na educação do campo através da formação de seus professores. O MST se mostra mais próximo que as prefeituras ou secretarias de educação, o que acentua a interpretação de que há um vácuo, um vazio estatal nos horizontes da educação do campo:

"Realmente falta formação. Nós tivemos um ou outro curso pela prefeitura, mas igual ao de todo mundo e acho que uma pós-graduação seria interessante... Direcionar pra reforma agrária. Porque nós temos já a formação, só que foi um dia só e foi do MST. E a graduação não ajuda muito porque na graduação eles não querem nem saber da reforma agrária, e latifundiários têm pavor da reforma agrária. Eu acho que é por aí, uma pós-graduação." (M.)

"Acho a formação continuada algo muito importante, mas que deve ser proposta pelo próprio governo. Falar que deveria sim ter uma formação específica para educadores do campo. Em que sentido? Até mesmo para a gente conhecer melhor. Por exemplo, eu sou de educação física e preciso saber especificidades. Aí quando vamos trabalhar a questão do solo já fica a desejar. Tem que pesquisar, pesquisar 
muito mais. Eu não contaria mentiras, digo mesmo que não entendo. A minha formação não é para isso..." (J.)

"Tem o HTPC e a secretaria oferece alguns cursos. Mas não especificou para o campo. Oferece alguns cursos, mas não para o campo. Eu falo assim que a gente que tem que entrar na Internet procurar, alguns simpósios, alguma coisa para ir nos orientando, alguns artigos. A gente está buscando saber, está mais atualizado nesse sentido. Mas eu falo que falta porque há necessidade até mesmo da gente pegar outras escolas." (M.).

Os excertos sinalizam uma reelaboração tácita, individual. As práticas e falas sinalizam que a ação chega antes. A mudança é contingência.

Há para os professores entrevistados a clareza de que o Estado deveria assumir maior responsabilidade na formação continuada. Criar estratégias específicas para a educação do campo. Quando dizem “a gente tem que buscar”, entendemos como ter que recomeçar da estaca zero. A formação continuada não continua de onde eles pararam, não considera aonde chegaram: a escola do campo.

\section{Os saberes em novos moldes: outras sequências e objetivos}

Os objetivos das aulas e a adoção das sequências didáticas sofrem modificações, e isso leva à consideração de que a base de conhecimentos dos professores passa por adaptações atreladas ao local específico de trabalho, porque os elementos acima colocados passam a girar em torno do local e suas relações com o global, o Brasil. A cidade não é uma próxima etapa no desenvolvimento do campo. Os objetivos, conteúdos e sequências não têm o sentido de se adaptar ao urbano, mas encontrar lugar no modelo de país a ser defendido, construído. E esse lugar será conquistado respeitando-se as especificidades e a cultura dos povos do campo.

A cisão entre campo e cidade é verificada nos momentos em que os professores ressaltam que, ao lecionar na escola da área urbana em Araraquara, os colegas se preocupam mais em transmitir os conteúdos curriculares “oficiais” e manter o domínio da sala, evitando a indisciplina. Assim, lá se balizam pelos saberes eruditos de Barbier (1996), que seriam similares aos saberes das disciplinas ou saberes disciplinares de Tardif, Lessard e Lahaye (1991) e Gauthier et al. (1998). Já na escola do campo os educadores se preocupam também com os relacionamentos, a humanização das relações; os saberes pedagógicos são os mais atingidos, pois se submetem a outros modelos e tempos.

Vimos ainda nessa dimensão, que é a da prática pedagógica, uma valorização do ensino de conteúdos conceituais (COLL, 1997), assim como de sequências didáticas mais integradoras, socializantes e dinâmicas. As aulas no campo parecem se aproximar da perspectiva de Freinet (1974), pois são aspectos que norteiam as experiências práticas na extensa área da escola e até mesmo nos lotes do assentamento. Adaptações que os professores são obrigados a fazer, pela especificidade do lugar e sua história.

São tantas e tão tênues adaptações que a reflexão-na-ação ganha amplitude e urgência tornando-se fomentadora de saberes que, por seu turno, são premidos pela necessidade de conhecer as histórias do lugar e seus sujeitos. Esses saberes estão articulados às experiências vivenciadas na escola; portanto, advêm e dependem da mobilização dos saberes da experiência (PIMENTA, 2005) ou de ação (BARBIER, 1996). Acreditamos, a partir de nossas observações e dos dados obtidos, que a junção desses elementos 
modifica as estratégias da docência. A docência do campo é diferente da docência na cidade, e o seguinte excerto sustenta esse olhar:

"Não é que dá mais trabalho, aula acaba
ficando muito técnica, muito teórica na
cidade porque você trabalha realmente
o currículo na base do currículo nacio-
nal, aquela parte diferenciada você deixa
um pouco de lado. (...) Por exemplo, aula
prática que eu vou trabalhar sobre solo,
já tem uma aula formulada com base na
teoria científica que pensa a aula prática.
Então são todas aulas diferenciadas, né?
Eu já tenho roteiro e quando chega mais
ou menos na época de acordo com o cur-
rículo eu começo a trabalhar. Aqui temos
aula de campo, visitas aos lotes. A gente
utiliza a cozinha experimental." (M).

Defendemos a ideia de que as modificações decorrentes desse processo interferem nas aulas e nos saberes pedagógicos. Ressaltaremos a seguir reflexões que nos levaram a conceber traços de modificação na relação dos professores com os saberes da educação, com o conteúdo, e também na dimensão do relacionamento professor $\mathrm{x}$ aluno.

\section{Outros olhares sobre os conteúdos curriculares e sobre os alunos}

Já citamos a questão da modificação das aulas, das sequências didáticas, aqui apontamos que há também o rearranjo das sequências do conteúdo e do modo como os conteúdos são selecionados. O currículo é trabalhado "na escola do campo para o campo”. Zabala (2002) defende que a adaptação e enriquecimento das sequências de conteúdo atuam para aproximá-los da realidade e facilitam a aprendizagem dos alunos. As sequências do conteúdo se adaptam ao calendário de colheitas, safras, chuvas e geadas.
Personagens históricos ganham outras leituras, movimentos sociais são estudados. $\mathrm{O}$ ensino baseado na sequência tradicional e no currículo oficial é substituído por sequências de conteúdos que partem da observação e são seguidos da pesquisa, privilegiando assim a realidade local, passando pelo registro até chegar à generalização. Exemplos são as aulas ministradas nos lotes, na cozinha e em todos os espaços possíveis. Nessas aulas há um aguçamento da curiosidade tanto dos alunos quanto dos professores. O excerto apresentado a seguir expõe uma prática concreta a esse respeito.

"É tudo baseado em projetos definidos no começo do ano. Então a horta, o que vai ser trabalhado dentro da horta, qual será a contribuição de inglês e português. Trabalhamos com alimentação, e cada professor vai dando sua contribuição dentro do projeto. E aí a gente desenvolve ao longo do ano. A gente também considera a parte comum e faz as avaliações em cima dos complexos, dos projetos que têm aqui. Então tudo é contemplado e a gente faz uma aula na cozinha experimental, faz uma pergunta sobre aquilo. Sempre relacionando com a vivência deles. Então a gente considera diferentes avaliações, que a gente fala que são os blocos. Então os espaços que a gente luta são considerados, a evolução do aluno é considerada. É lógico que tem a parte que tem de ser cobrada e é avaliado por isso também, inclui um conjunto." (M.)

Nessas aulas os alunos se tornam sujeitos da construção e reconstrução do saber, ensinando ao lado do educador, igualmente sujeito do processo, o que constitui um paralelo à visão de Freire (1997) quando este explicita a exigência da rigorosidade metódica advinda da condição de moderador. Para ele:

O educador democrático não pode negar-se o dever de, na sua prática docente, reforçar 
a capacidade crítica do educando, sua curiosidade, sua insubmissão. Uma de suas tarefas primordiais é trabalhar com os educandos a rigorosidade metódica com que devem se aproximar dos objetos cognoscíveis. E esta rigorosidade metódica não tem nada a ver com o discurso bancário meramente transferidor do perfil do objeto ou do conteúdo. (FREIRE, 1997, p.29).

Sobre as relações interpessoais, sabemos que influem profundamente na aprendizagem e são bases para a docência. Nesta temática os professores sugeriram a ocorrência de um processo de humanização das relações, de humanização do trabalho e do lugar através da ampliação das possibilidades, das experiências, vivências. Também destacaram que desse processo decorre uma valorização da profissão, a possibilidade de ampliação de autonomia, de participação na gestão educacional, de proximidade com a comunidade local e defenderam que tais fatores são decisivos na motivação pelo continuar, pelo recomeçar, na escola do campo.

Entretanto, a ascensão de novos modelos de relacionamento entre professor e alunos, vistos como mais próximos e horizontais, inicialmente surpreende os professores vindos da cidade e os aflige ao propor como exigência a humanização que desconstrói visões sobre a docência como profissão técnica e desumanizadora de relações. Nas vivências de sala de aula entre professor aluno revive-se o afeto, o carinho e a cumplicidade considerada perdida nas relações das grandes escolas urbanas.

Na fala dos professores há indícios de uma aproximação entre esses sujeitos, o respeito de um para com o outro e vice versa, o que enriquece a ação educativa e a relação humana, mas se exige dos professores a percepção de que o ato educativo é muito amplo, vai além do ensinar.
"Tem uma relação humana, é com os alunos, muito maior que o tem na cidade. Há uma relação uma afetividade maior, tem carinho. Vamos dizer assim. Quando falo: - Vou dar aula no assentamento! Eu venho com toda alegria, com todo coração. E isso aí é um diferencial." (R.)

"As crianças são carinhosas, elas são mais dóceis. Trabalhei na cidade por onze anos e meio. Aqui realmente, o relacionamento do educador com as crianças não é só de ensino. Ali na sala de aula é de amizade e solidariedade, amor. É diferente na cidade. Eu sempre fui muito apegada às minhas crianças. Mas existem professores que não gostam de desenvolver aquilo que o ser humano precisa. Durante a vida." (M.)

Segundo os professores, os pais e as famílias de modo geral também influenciam a redefinição de elementos da docência, eles trazem outro viés à questão da valorização desses profissionais, impulsionam e legitimam o trabalho dos professores ao acompanhar de perto o desenvolvimento dos filhos.

Depreende-se das narrativas a visão de que os alunos do campo são sujeitos com o poder de alimentar e realimentar o processo de ensino-aprendizagem, pois além de fomentarem a autoestima dos professores são considerados professores igualmente na medida em que “também ensinam” uma série de coisas sobre a realidade e a própria vida. Buscando em Freire (1997) a compreensão da influência que os alunos possuem sobre a prática docente, confirmamos essa tendência de ver nesses sujeitos a razão das buscas por melhoria, por adaptação. Eles nos obrigam a rever nossos conhecimentos, nossas limitações. Para Freire (1997), essa preocupação é parte essencial ao ato educativo e parte da reciprocidade de apreciação: 
"Não posso escapar à apreciação dos alunos. E a maneira como eles me percebem tem importância capital para o meu desempenho (...). Mas, devo estar atento à leitura que fazem da minha atividade com eles. Precisamos aprender a compreender a significação de um silêncio, ou de um sorriso ou de uma retirada da sala" (p. 14).

Para os entrevistados, as diferenças se pautam principalmente pelo fato de os alunos possuírem laços mais estreitos com as famílias, por passarem grande parte do dia em locais comuns como a plantação, porque existe uma valorização dos núcleos familiares e porque os pais assim próximos se tornam mais presentes nas questões da criação dos filhos e da educação. As famílias estão presentes em várias ocasiões e se interessam pela educação das crianças, demandam educação de qualidade e reconhecem o valor não apenas dos conhecimentos do campo esquecidos, mas visíveis nos saberes das ervas, da terra, do plantio, das luas e cheias. Valorizam também o acesso aos saberes legitimados pela sociedade, conhecimentos de leitura, escrita, matemática e tudo o que é cobrado no meio urbano-industrial. A escola, como indica Ferrante (2005), é o principal local de socialização do assentamento, é nela que acontecem as campanhas de vacinação, as rezas, as festas, as reuniões. Os anfitriões dela são os professores, eles estão mudando para desenvolver essa e outras funções.

\section{Considerações Finais}

A partir do acesso às narrativas de quatro professores de uma escola do campo e das leituras sobre a temática, observamos que as trajetórias docentes naquele espaço são marcadas por vários elementos, dentre os quais enfatizamos: o grande desconhecimento sobre o contexto, o medo perante um cotidiano desconhecido, o enfrentamento da demanda por adaptações da prática, da postura e da concepção acerca do papel do professor, a pressão pela aproximação junto à comunidade local e a demanda por novos modelos de relacionamento entre professor e aluno.

Na chegada à escola do campo, os primeiros elementos decorrem de uma sedimentação da percepção historicamente construída sobre o que seja o campo, a reforma agrária e a educação rural. Percepção que é orientada por uma visão do campo como lugar de pobreza, precariedade, ou seja, de subdesenvolvimento. A escola rural, hoje denominada do campo, é imaginada como uma escola de madeira, barraca, e os alunos do campo ainda são vistos como pobrezinhos, como trabalhadores das lavouras. Essas concepções prévias definem uma postura inicial que, ao mesmo tempo em que se revela curiosa, se mostra preenchida por medo e ansiedade maiores do que aqueles do início da docência no meio urbano, na qual a tendência é a reprodução do ruralismo pedagógico.

Esse choque mostra que precisamos pensar o sentido de ser profissional no magistério a partir de suas especificidades. Para tanto, ressaltamos - como fazem Knowles \& Cole (1994) - que o aprender a ensinar é processo complexo que envolve os fatores afetivos, cognitivos, éticos, de desempenho, entre outros, sabendo assim que não se possui até o momento um referencial teórico único sobre a aprendizagem profissional que possa nortear todos os processos de desenvolvimento profissional.

A inexistência de bases conceituais e epistemológicas sobre a docência no e do campo obriga os seus professores a assumirem riscos e deixar de usar como proteção um sistema, os programas e os textos. Esses profissionais têm de liderar um movimento cuja consequência é a construção e atualização 
das competências necessárias para o exercício, pessoal e coletivo, da autonomia e da responsabilidade (NÓVOA, 2002).

Vimos lampejos desse movimento nas escolas do campo, a docência como assunção de um risco, a aposta em outros caminhos, o magistério em corda bamba, e sem rede de proteção.

Sobre as ressignificações da docência, observamos a assunção de responsabilidades diferentes na formação dos alunos. O "fazer parte de algo maior”, que eles citam, os leva a um comprometimento com o desenvolvimento de todo o assentamento, de suas famílias e condições econômicas. Assim, mostram mais disponibilidade em ampliar sua atuação naquilo que a comunidade precisar, encontrando dificuldades em definir as fronteiras da docência em várias ocasiões.

Quanto aos saberes, utilizamos a classificação de Tardif, Lessard \& Lahaye (1991), percebemos que são atingidos/modificados inicialmente os saberes pedagógicos porque repousam inicialmente em novos modelos de relacionamento entre professores e alunos e por novos ritmos e espaços. Também percebemos a ressignificação, ou melhor, o desenvolvimento de novos saberes curriculares premidos pela característica da escola do campo de "situar" os programas curriculares, as diretrizes de acordo com a realidade do campo, respeitando valores, datas e conhecimentos dos sujeitos a ele pertencentes. Os saberes das ciências da educação foram reformulados, considerados com base em outra realidade, os professores tiveram de fugir da leitura do "mesmo", pois falar em indisciplina, em perspectivas da educação, em tecnologias prescindiu do estabelecimento de outro perfil de aluno e escola.

E quanto aos saberes da experiência, vimos que foram profundamente ativados, porque não havia âncoras significativas para os professores entrevistados, nada que subsidiasse a interpretação do choque da realidade, do confronto com a realidade do campo. O velho conhecido campo é de fato um novo contexto a conhecer, em que apenas a experiência vivida na realidade imprime interpretações objetivas e possibilidades de decisão teórico-metodológica aos professores ex-forasteiros.

Resvalar para uma reflexão mais ampla, que enseja a função ou a definição de um papel político para o professor do campo é ponto melindroso. O distanciamento dos professores entrevistados em relação a esse ponto sinaliza que a educação do campo continua sem uma reflexão sobre sua essência: a existência de conflitos em seu bojo, que transcendem aos aspectos ligados ao nível educacional apenas, e são estranhos ao professor forjado no microcosmo das salas de aula urbanas. Para além desta consideração, cremos que o fato de não explicitarem uma concepção própria sobre reforma agrária acena que há um processo de reflexão sobre a condição dos sujeitos do campo, mas ela não ultrapassa fronteiras como o currículo e as políticas públicas verticalmente descendentes.

Ao falarem sobre a solidão de suas trajetórias, a inexistência de iniciativas de formação continuada (mesmo que existam relações interpessoais de apoio dos mais experientes para os mais jovens), os professores indicam e justificam, de certo modo, as razões pelas quais não chegaram àquele processo reflexivo que é ressaltado por Diniz-Pereira e Zeichner (2005). Os referidos autores expõem esse projeto como aquele que explicita a ultrapassagem da dimensão técnica de ensino e, assim, constitui um profissional que compreende o contexto social mais amplo, compromissado com a mudança social. Isso porque a reflexão neste caso deve ser um processo coletivo, e sem o apoio 
governamental e o resgate histórico do campo, é difícil para a escola cimentar caminho para esse avanço.

\section{Referências}

BARBIER, J. M. (Org.). Savoirs théoriques et savoirs dáction. Paris: PUF, 1996.

CANÁRIO, R. A escola tem futuro: das promessas às incertezas. São Paulo: Artmed, 2006.

CASTELLS. M. A sociedade em rede. São Paulo: Paz e Terra, 2002.

COLL, C. Psicologia e currículo: uma aproximação psicopedagógica à elaboração do currículo escolar. São Paulo: Ática, 1997.

CONTRERAS, J. A autonomia de professores. São Paulo: Cortez, 2002.

DINIZ-PEREIRA, J. E.; ZEICHNER, K. Pesquisa dos educadores e formação docente voltada para a transformação social. Cadernos de Pesquisa, v. 35, p 63-80, 2005.

EDWARDS, V. Os sujeitos no universo escolar. São Paulo: Ática, 1997.

ELBAZ, F. Knowledge and discourse: the evolution of research on teacher thinking. In: DAY, C. Insights into teachers thinking and practice. London: Falmer, 1990.

FERRANTE, V. L. S. B.; BARONE L. A. O lugar dos assentamentos no desenvolvimento local/regional: dilemas e perspectivas futuras. Revista UNIARA v.1, n.17/18, p.155180, 2005.

FIAMENGUE, E. C. Infância, educação e reforma agrária. In: Escritos Pedagógicos, v. 2, p. 09-25, 2004.

FORQUIN, J. C. Escola e cultura: as bases sociais e epistemológicas do conhecimento escolar. Porto Alegre: Artes Médicas, 1993.
FREINET, C. A educação pelo trabalho. Lisboa: Presença, 1974.

FREIRE, P. Pedagogia da autonomia: saberes necessários à prática educativa. São Paulo: Paz e Terra, 1997.

GAUTHIER, C. et al. Por uma teoria da pedagogia: pesquisas contemporâneas sobre o saber docente. Ijuí: UNIJUÍ, 1998.

GOHN, M. G. Teorias dos movimentos sociais: paradigmasclássicosecontemporâneos. São Paulo: Loyola, 1997.

IMBERNÓN, F. Formação docente e profissional: formar-se para a mudança e a incerteza. São Paulo: Cortez, 2005.

KAUTSKY, K. A questão agrária. São Paulo: Nova Cultura, 1986.

KNOWLES, J. G.; COLE, A. L. Through preservice teachers'eyes: experiences trough narrative and inquiry. New York: McMillan College Publishing Co., 1994.

LENIN, V. I. O desenvolvimento do capitalismo na Rússia: o processo de formação do mercado interno para grande agroindústria. São Paulo: Nova Cultura, 1988.

MEIHY, J. C. S. B. Manual de história oral. São Paulo: Loyola, 2005.

NÓVOA, A. Formação de professores e profissão docente. Lisboa: Dom Quixote, 2002.

PIMENTA, S. G.; GHEDIN, E. Professor reflexivo no Brasil. São Paulo: Cortez, 2002.

Saberes pedagógicos e atividade

docente. São Paulo Cortez, 2005.

SCHÖN, D. A. The reflective practitioner: how professionals think in action. USA: Basic Books, 1983. 
SOUZA, E. C.; ABRAHÃO, M. H. M. B. (Orgs.). Tempos, narrativas e ficções: a invenção de si. Porto Alegre: EDIPUCRS, 2006.

TARDIF, M.; LESSARD, C.; LAHAYE, L. Os professores face ao saber: esboço de uma problemática do saber docente. Teoria \& Educação, n.4, Porto Alegre: Pannônica, 1991.

WHITAKER, D. C. A.; ANTUNIASSI, M. H. R. Escola pública localizada na zona rural: contribuições para a sua estruturação. Cadernos Cedes n.33, p.9-42, 1992.

WHITAKER, D. C. A. Sociologia Rural: questões metodológicas emergentes. Presidente Venceslau: Letras à Margem, 2002.

ZABALA, A. Enfoque globalizador e pensamento complexo: uma proposta para o currículo escolar. Porto Alegre: ArtMed Editora, 2002.

Recebido em: 30/04/2012

Aceito em: 21/05/2012 